PPPL-3444

PPPL-3444

UC-70

Observation of Modes at Frequencies Near

the Second Alfvén Gap in TFTR

by

E. Fredrickson, J.W. Van Dam, R.V. Budny, D. Darrow, G.Y. Fu,

J. Hosea, C.K. Phillips, and J.R. Wilson

April 2000

$\int D \sqrt{D} \int \sqrt{\zeta} \int\left[\begin{array}{l}\text { PAINCETON } \\ \text { PLABMA PHYSICS } \\ \text { LABOAATOAY }\end{array}\right.$

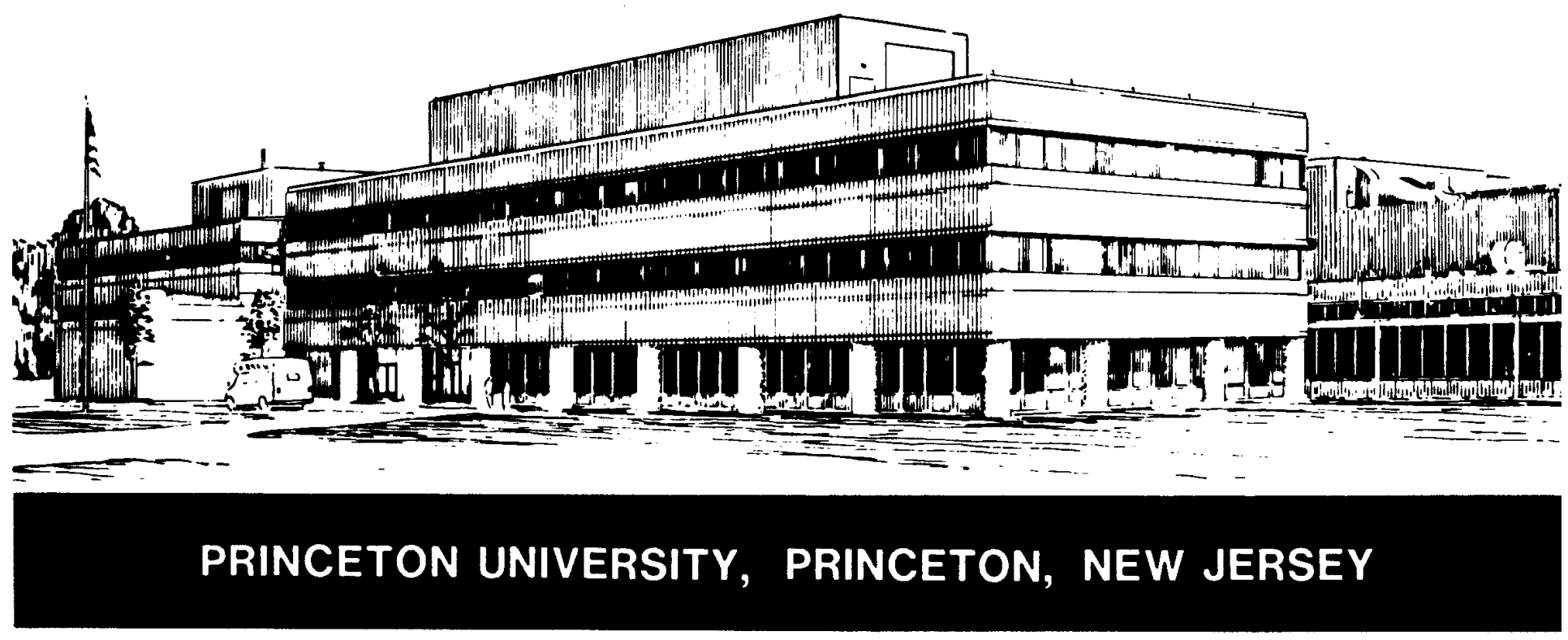




\section{PPPL Reports Disclaimer}

This report was prepared as an account of work sponsored by an agency of the United States Government. Neither the United States Government nor any agency thereof, nor any of their employees, makes any warranty, express or implied, or assumes any legal liability or responsibility for the accuracy, completeness, or usefulness of any information, apparatus, product, or process disclosed, or represents that its use would not infringe privately owned rights. Reference herein to any specific commercial product, process, or service by trade name, trademark, manufacturer, or otherwise, does not necessarily constitute or imply its endorsement, recommendation, or favoring by the United States Government or any agency thereof. The views and opinions of authors expressed herein do not necessarily state or reflect those of the United States Government or any agency thereof.

\section{Availability}

This report is posted on the U.S. Department of Energy's Princeton Plasma Physics Laboratory Publications and Reports web site in Calendar Year 2000. The home page for PPPL Reports and Publications is: http://www.pppl.gov/pub_report/

DOE and DOE Contractors can obtain copies of this report from:

U.S. Department of Energy

Office of Scientific and Technical Information

DOE Technical Information Services (DTIS)

P.O. Box 62

Oak Ridge, TN 37831

Telephone: (865) 576-8401

Fax: (865) 576-5728

Email: reports@adonis.osti.gov

This report is available to the general public from:

National Technical Information Service

U.S. Department of Commerce

5285 Port Royal Road

Springfield, VA 22161

Telephone: $1-800-553-6847$ or

(703) $605-6000$

Fax: (703) 321-8547

Internet: http://www.ntis.gov/ordering.htm 


\title{
Observation of Modes at Frequencies Near the Second Alfvén Gap in TFTR
}

\author{
E. Fredrickson, J. W. Van Dam*, R. V. Budny, \\ D. Darrow, G. Y. Fu, J. Hosea, C. K. Phillips, J. R. Wilson \\ Princeton Plasma Physics Laboratory, Princeton, New Jersey \\ *Institute for Fusion Studies, University of Texas at Austin, Austin, Texas
}

\begin{abstract}
Modes have been observed near the frequency of the second Alfvén gap during off-axis H-minority heating experiments in the circular cross-section Tokamak Fusion Test Reactor. The observation of these modes is surprising in that the second gap, which is generally opened with ellipticity, is expected to be small, of order $(r / R)^{2}$. A model is proposed in which the second gap is opened by the fast ion beta, which is shown to be able to introduce mode coupling, much as toroidal effects introduce mode coupling for Toroidal Alfvén Eigenmodes (TAE). The modes are seen with and without accompanying TAE mode activity.
\end{abstract}

\section{INTRODUCTION}

Ion Cyclotron Range of Frequency (ICRF) conditioning and H-minority heating experiments have been done under a wide range of conditions on the Tokamak Fusion Test Reactor (TFTR), predominantly with the resonance near the magnetic axis. Two types of modes at frequencies near the first Alfvén gap were commonly observed during these ICRF heating experiments. These modes were identified as Toroidal Alfvén Eigenmodes (TAE) and a fast ion mode [1], probably the Energetic Particle Mode (EPM) [2]. Damage to plasma facing components ascribed to fast ion losses driven by these modes $[3,4]$ encouraged efforts to avoid them. Moving the ICRF resonance from near the magnetic axis to the high field side beyond the $\mathrm{q}=1$ radius 
was found to greatly reduce the frequency of occurence and amplitude of the TAE modes.

The off-axis resonance on the high field side introduced a third mode. Approximately $90 \%$ of the plasmas with the resonance off-axis on the high field side and $\geq 4 \mathrm{MW}$ of RF power had modes near the frequency of the second Alfvén gap. These off-axis RF experiments were performed primarily to condition the RF systems and were performed for a limited range of parameters. The "second gap" modes were observed under the following conditions: $\mathrm{Ip}=1.3 \mathrm{MA}, \mathrm{B}_{\mathrm{tor}}=2.5 \mathrm{~T}, \mathrm{f}_{\mathrm{ICRF}}=43 \mathrm{MHz}$, $\mathrm{R}_{0}=2.62 \mathrm{~m}, \mathrm{R}_{\text {res }}(\mathrm{H})=2.35 \mathrm{~m}, \mathrm{a}_{\mathrm{p}}=0.97 \mathrm{~m}$. The spectral peaks at the second gap frequency are not harmonics of TAE modes, nor non-linear mixing of the TAE activity. As desired, in these experiments the TAE activity is often weak or nonexistent.

The observation of modes in the range of frequencies of the second gap is surprising in the circular TFTR plasmas since the second gap is generally thought of as the Alfvén gap that is induced primarily by ellipticity. Toroidicity effects on the second gap are negligibly small, of order $\varepsilon^{2}$, where $\varepsilon=r / R_{0}$ is the inverse aspect ratio. However, it has been predicted that the second Alfvén gap can be opened by the presence of an energetic trapped ion population $[5,6]$. Estimates suggest that there is sufficient fast ion beta in these TFTR plasmas to open the gap and drive the mode.

In a very few of the on-axis ICRF heating experiments, peaks in the magnetic fluctuation spectra were observed at twice the TAE frequency. These peaks were only observed in the presence of strong TAE or EPM activity and the frequency peaks were sums of the TAE frequencies, suggesting that these modes represent non-linear mode mixing of the TAE modes. The data will not be discussed in more detail in this paper. 


\section{EXPERIMENTAL OBSERVATIONS}

The "second gap" modes are seen at frequencies near the second Alfvén frequency gap, approximately $407 \mathrm{kHz}$ to $411 \mathrm{kHz}$. The modes appear as short bursts characteristically lasting less than or of order $50 \mathrm{msec}$. The modes are not harmonics of the TAE modes sometimes seen in these same plasmas. This can be seen in Figure 1 where the spectrogram of Mirnov coil data shows the TAE activity in the frequency range from $185 \mathrm{kHz}$ to $200 \mathrm{kHz}$ and the $2^{\text {nd }}$ Gap Mode Activity in the range $398 \mathrm{kHz}$ to $422 \mathrm{kHz}$. The time behavior of the $2^{\text {nd }}$ Gap Modes is qualitatively different than that of the TAEs and the harmonics of the TAEs would be at frequencies lower than $400 \mathrm{kHz}$.

The mode behavior is correlated with the sawtooth period, illustrated in Fig. 1 by the inclusion of a central soft x-ray chord showing the sawtooth times. Most commonly the mode frequency chirps down, changing frequency in each burst by about $5 \mathrm{kHz}$ in the $30-50 \mathrm{~ms}$ that it is present, and in this case by about $20 \mathrm{kHz}$ over the period of the sawtooth. The bursts often consist of multiple modes, separated in frequency by a few $\mathrm{kHz}$, e.g., the bursts between 4.3 and $4.4 \mathrm{~s}$ and between 4.4 and $4.5 \mathrm{~s}$.

The TAE (and EPM) modes propagate in the ion diamagnetic drift direction [2] but the $2^{\text {nd }}$ Gap Modes propagate in the opposite direction. This can be seen in Figures $2 a$ and $2 b$. In Figure 2a is shown the phase information from the Fourier analysis of the $2^{\text {nd }}$ Gap Mode burst between 4.28 and $4.3 \mathrm{sec}$ in Fig. 1 . The data is best fit assuming a dominant toroidal mode number, $\mathrm{n}=+4$. The slope of the fitted line gives the toroidal propagation direction. For comparison, the phase information from the TAE mode in Fig. 1 in the same time period is shown in Fig. 2b. As can be seen, the direction of propagation is reversed. The phase data from this particular TAE mode is best fit with a toroidal mode number of $n=-5$. The lower frequency TAE mode is best fit with $n=-4$ and the higher frequency mode with $n=-6$.

In the course of the RF conditioning campaigns, variations in limiter conditions resulted in a range of central plasma densities from $3.2 \times 10^{19} \mathrm{~m}^{-3}$ to $4.2 \times 10^{19} \mathrm{~m}^{-3}$. From this data set it was possible to examine the scaling of the mode frequency with 
density. The mode frequency is in good agreement with the predicted frequency for the second gap and scales as $n_{e}(0)^{-1 / 2}$, consistent with Alfvén-like modes [Fig. 3]. The existing data set has no toroidal field variation from which to derive a magnetic field scaling.

With the off-axis resonance on the high field side, the sawteeth were not stabilized in these plasmas in the range of input power levels $(<5 \mathrm{MW})$. The sawteeth flatten the density profile in the core region, dropping the density within the $\mathrm{q}=1$ surface. The chirping of the mode frequency is consistent with the time evolution of the central density. In Figure 4 the mode frequency evolution is overlaid with the $2^{\text {nd }}$ Gap frequency calculated using the central density, $\mathrm{f}_{\mathrm{TAE}} \equiv 0.96 \mathrm{~V}_{\mathrm{Alfvén}}(0) /\left(2 \pi \mathrm{qR}_{0}\right)$ including a $4 \%$ correction to qualitatively match the mode frequency evolution. The second gap mode frequency drop is consistent with the recovery of density peaking between sawtooth crashes, indicating that the modes are localized within the $q=1$ surface.

The linear growth rate of the mode, shown for two representative cases in Fig. 5, varies from about $2 \times 10^{4} / \mathrm{s}$ to $5 \times 10^{2} / \mathrm{s}$. The rate can be nearly constant over three efoldings of the mode amplitude. The mode amplitude then saturates and can remain nearly constant or have slow variations. Sawtooth crashes terminate the bursts. It is assumed that sawteeth flatten the fast ion beta within $\mathrm{q}=1$. This observation is consistent with the mode's drive being within $\mathrm{q}=1$.

The saturation amplitude of the magnetic fluctuation (in Gauss) is roughly linearly proportional to the linear growth rate [Fig. 6]. This conclusion is contingent on the accuracy of the assumption that the mode structure does not change substantially during the period of the mode growth, so that the external magnetic fluctuation level is proportional to the internal magnetic fluctuation level. This linear correlation between the saturated magnetic fluctuation amplitude and the linear growth rate is not consistent with the normal saturation mechanism arising from wave trapping of fast ions where the saturated wave amplitude is proportional to the square root of the growth rate [7]. 
More complicated growth behavior is also seen as illustrated in Fig 7. The mode amplitude does not necessarily remain constant after "saturation". This could reflect changes in equilibrium parameters such as the density profile or fast ion distribution. It could also result from the non-linear effects in a weakly driven system when the mode linear growth rate is slow compared to the fast ion replenishment rate [7].

\begin{abstract}
ANALYSIS
The RF heat deposition and tail formation are modeled with the TRANSP code [8] and the SPRUCE RF package. Sawteeth are assumed to affect the fast ion tail population, and this is modeled in TRANSP with a mixing model that assumes a Kadomtsev-type flux reconnection at each sawtooth crash. The RF resonant position is off-axis on the high field side, presumably resulting in few deeply trapped fast ions. The fast ion beta is calculated to vary from flat to hollow during the sawtooth cycle. Prior to each sawtooth crash the fast ion profile becomes hollow, peaking off-axis at a minor radius of about $15 \mathrm{~cm}$ in a $96 \mathrm{~cm}$ minor radius plasma [Fig. 8]. The sawtooth model used in this TRANSP run mixes the fast ion population within the reconnection layer.

The calculated RF power deposition layer is broad. However, the width depends on assumptions about the fast ion redistribution at each sawtooth crash and the $\mathrm{H}$ minority fraction that is assumed. The peak fast ion beta varies from about $0.6 \%$ just prior to a sawtooth crash, to about $0.4 \%$ after the sawtooth crash mixes the fast ions, flattening the profile. This fast ion beta is estimated to broaden the $2^{\text {nd }}$ Gap to about $10 \mathrm{kHz}$ from $4 \mathrm{kHz}$.

The hollow fast ion pressure profile prior to sawtooth crashes is a possible explanation for the "backwards" mode propagation. An alternative explanation is that high field resonance ICRF heating can create an inverted energy population (at constant magnetic moment). This can also provide a source of free energy to drive Alfvénic modes and in some cases this mechanism can couple strongly to counterpropagating modes [9]. More detailed calculations of the damping and driving terms
\end{abstract}


still need to be done. The agreement between the frequency evolution and the central density evolution suggest that the modes are most strongly affected by core (within $\mathrm{q}=1$ ) plasma parameters. This would be consistent with the supposition that the "backward" wave propagation is due to the hollow fast ion profile.

The TRANSP and SPRUCE code modeling predict a fast ion tail temperature of order $30-50 \mathrm{keV}$ at the center of plasma. The required tail energy for the precessional resonance for the $\mathrm{n}=4 \mathrm{EAE}$ at $400 \mathrm{kHz}$ is $\geq 1 \mathrm{Mev}$, thus it is unlikely that the precessional resonance is driving the mode. For the bounce resonance at $400 \mathrm{kHz}$, the condition is $\mathrm{E}_{\mathrm{hot}} \geq 900 \mathrm{keV} / l^{2}$ where $l$ is an integer. Thus, the bounce resonance condition can be approximately met for $1 \approx 3$. This high harmonic bounce resonance is peculiar to off-axis heating. The reason is that the tail temperature in off-axis heating cases is much lower than the on-axis cases so that the precessional drift resonance is not possible.

\section{SUMMARY}

Modes have been observed in the frequency range of the second Alfvénic gap in H-minority ICRF heated plasmas in TFTR. This observation is surprising in that the second gap is generally considered to be small in circular cross section plasmas. The mode is inferred to be a "core" mode, i.e., localized in some sense within the $\mathrm{q}=1$ surface. This follows from the observation that the time dependence of the mode frequency is consistent with the changes in the central density, with the appearance of the mode in the latter part of the sawtooth period when the central fast ion beta has peaked up, and with the direction of propagation. The last of these being explained in part by a hollow fast ion beta profile, which is only present in the core region. The modes are generally not observed during on-axis H-minority heating, but commonly observed during off-axis heating on the high field side (with the resonant layer outside the $\mathrm{q}=1$ surface). A model has been proposed that the beta of the fast ions opens the second gap, allowing instability. For TFTR parameters, the model predicts a gap width of approximately $10 \mathrm{kHz}$, which is $2.5 \%$ of the second gap frequency. If the backwards mode propagation is due to a hollow fast ion profile (as indicated in 
the TRANSP calculations), then instability due to wave-particle resonance at the magnetic curvature precessional frequency can occur only if the precessional frequency is reversed. This can indeed be the case for off-axis heating on the high field side. Thus, trapped fast ion pressure effects seem to explain several of the observed features of these second gap fluctuations.

\section{ACKNOWLEDGEMENTS}

This work was supported under DoE Contract No. DE-AC02-76-CHO-3073 with Princeton Plasma Physics Laboratory and DoE Contract No. DE-FG03-96ER-54346 with the Institute for Fusion Studies. 


\section{REFERENCES}

1. E. D. Fredrickson, Nucl. Fusion 35, 1457 (1995).

2. S. Bernabei, M.G. Bell, R. Budny, D. Darrow, E.D. Fredrickson, N. Gorelenkov, J.C. Hosea, R. Majeski, E. Mazzucato, R. Nazikian, C.K. Phillips, J.H. Rogers, G. Schilling, R. White, J.R. Wilson, F. Zonca, and S. Zweben, Physics of Plasmas 6, 1880 (1999).

3. R.B. White, E. Fredrickson, D. Darrow, M.Zarnstorff, R. Wilson, S. Zweben, K. Hill, Yang Chen, Guoyong Fu, Phys. Plasmas 2, 2871 (1995).

4. D. Darrow, S. J. Zweben, Z. Chang, C.Z. Cheng, M.D. Diesso, E.D. Fredrickson, E. Mazzucato, R. Nazikian, C.K. Phillips, S. Popovichev, M.H. Redi, R.B. White, J.R. Wilson, K. Wong, Nucl. Fusion 37, 939 (1997).

5. J. W. Van Dam, M. N. Rosenbluth, Bull. Am. Phys. Soc. 43, 1753 (1998).

6. B. N. Breizman, H. L. Berk, et al., 17th IAEA Fusion Energy Conference, Yokohama, Japan, 19-24 October 1998, paper IAEA-F1-CN-69/TH2/4.

7. H.L. Berk, B.N. Breizman, J. Fitzpatrick, M.S. Pekker, H.V. Wong, and K.L. Wong, Phys. Plasmas 3, 1827 (1996).

8. R. V. Budny, Nucl. Fusion 34, 1247 (1994), and references therein.

9. H.V. Wong, H.L. Berk, Physics Letters A 251, 126 (1999). 


\section{FIGURE CAPTIONS}

Figure 1. Spectrogram of the second gap modes and the TAE modes. A central soft $\mathrm{X}$-ray chord is included to illustrate the sawtooth times. (87838).

Figure 2a. Best fit to phase analysis of EAE burst at $407 \mathrm{kHz}, 4.28 \mathrm{sec}$ using a toroidal mode number of +4 , propagating in the counter-to-plasma current direction; nominally the ion diamagnetic drift direction.

Figure 2b Best fit to phase analysis of TAE mode at $192 \mathrm{kHz}, 4.28 \mathrm{sec}$ using a toroidal mode number of -5 , propagating in the nominal electron diamagnetic drift direction.

Figure 3. Frequency scaling of second gap modes with central density.

Figure 4. Spectrogram of the second gap modes. Dashed line shows the approximate central Alfvén frequency, $\mathrm{f}_{\text {Alfvén }} \approx \mathrm{V}_{\text {Alfvén }}(0) /(2 \pi \mathrm{qR})$.

Figure 5. The linear growth rate can vary by up to a factor of three, even within the same shot.

Figure 6. The saturated mode amplitude is proportional to the linear growth rate (here normalized to mode frequency).

Figure 7. The saturated amplitude of the bursts varies considerably in time during the bursts.

Figure 8. Fast ion beta before and after sawtooth crash. The q-profile is also shown. 
Figure 1
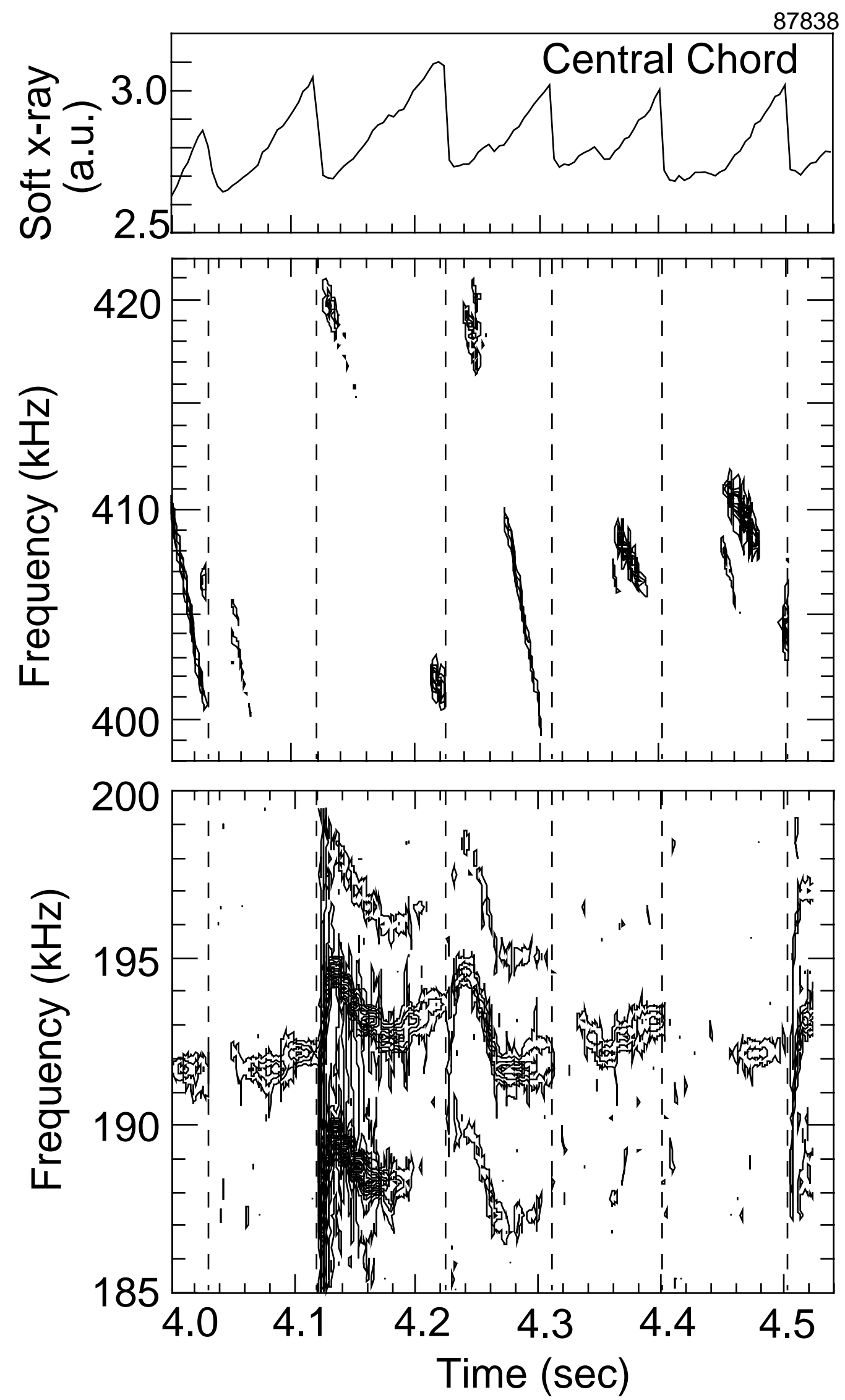
Figure $2 a$

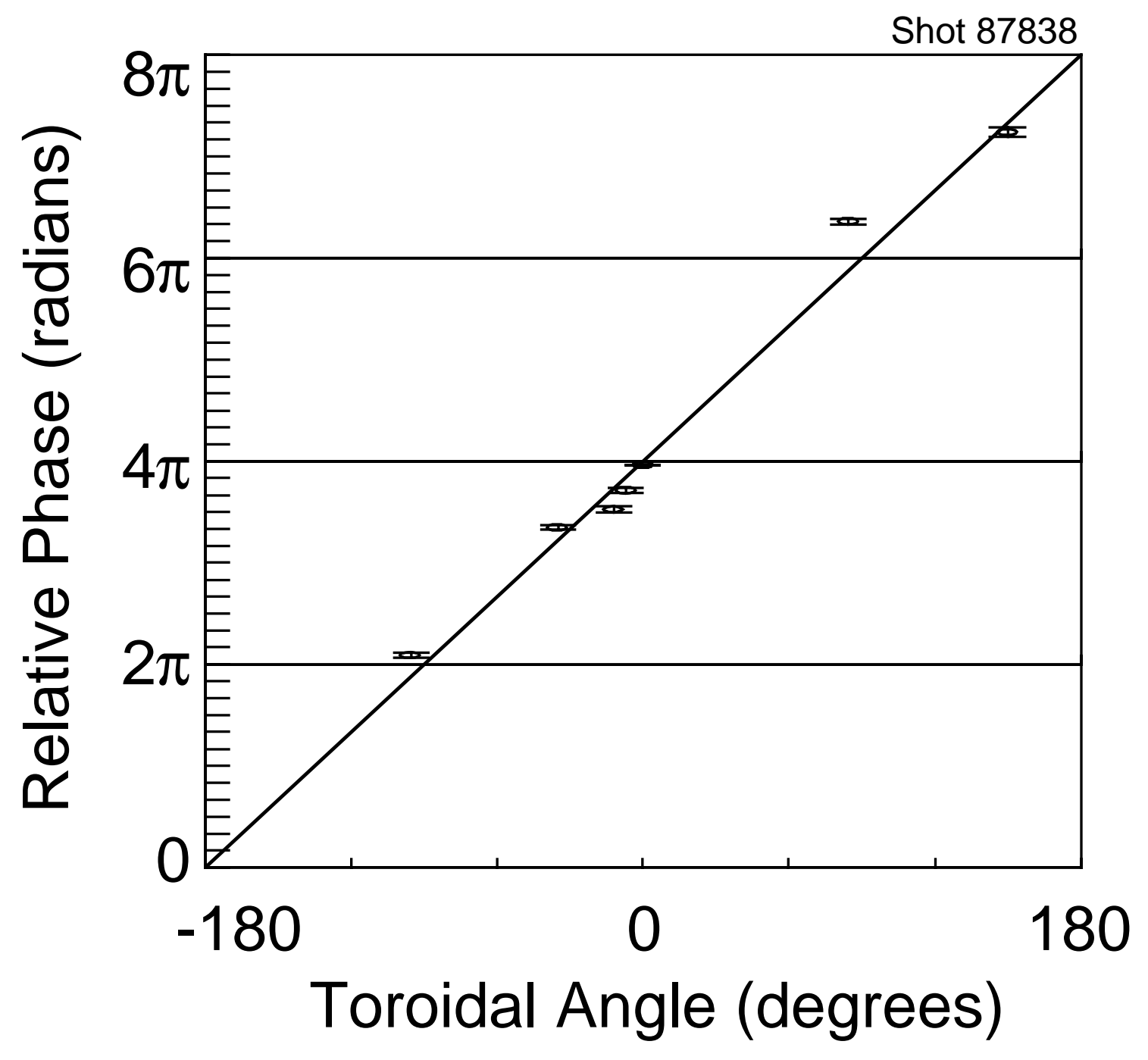


Figure 2b

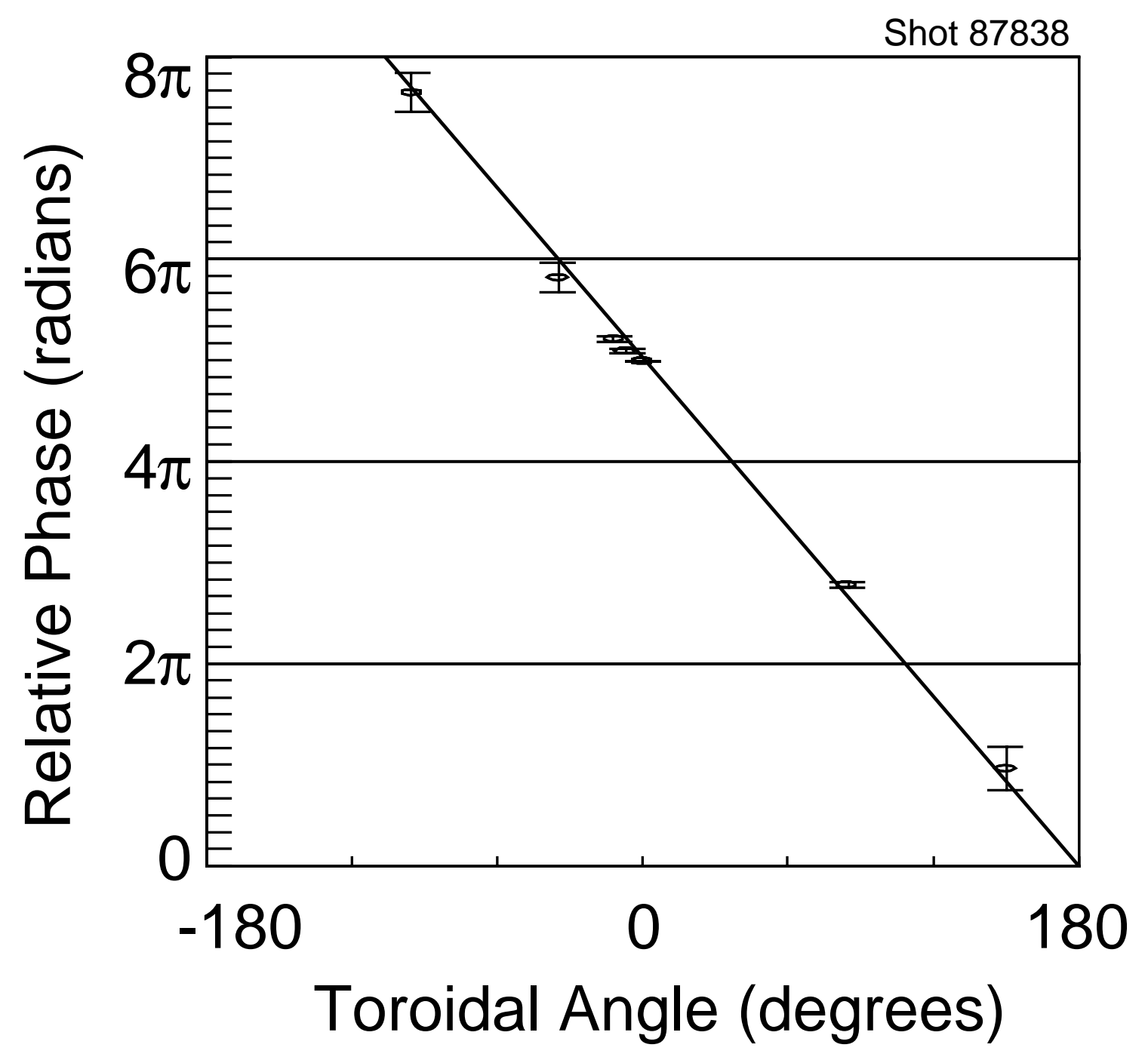


Figure 3

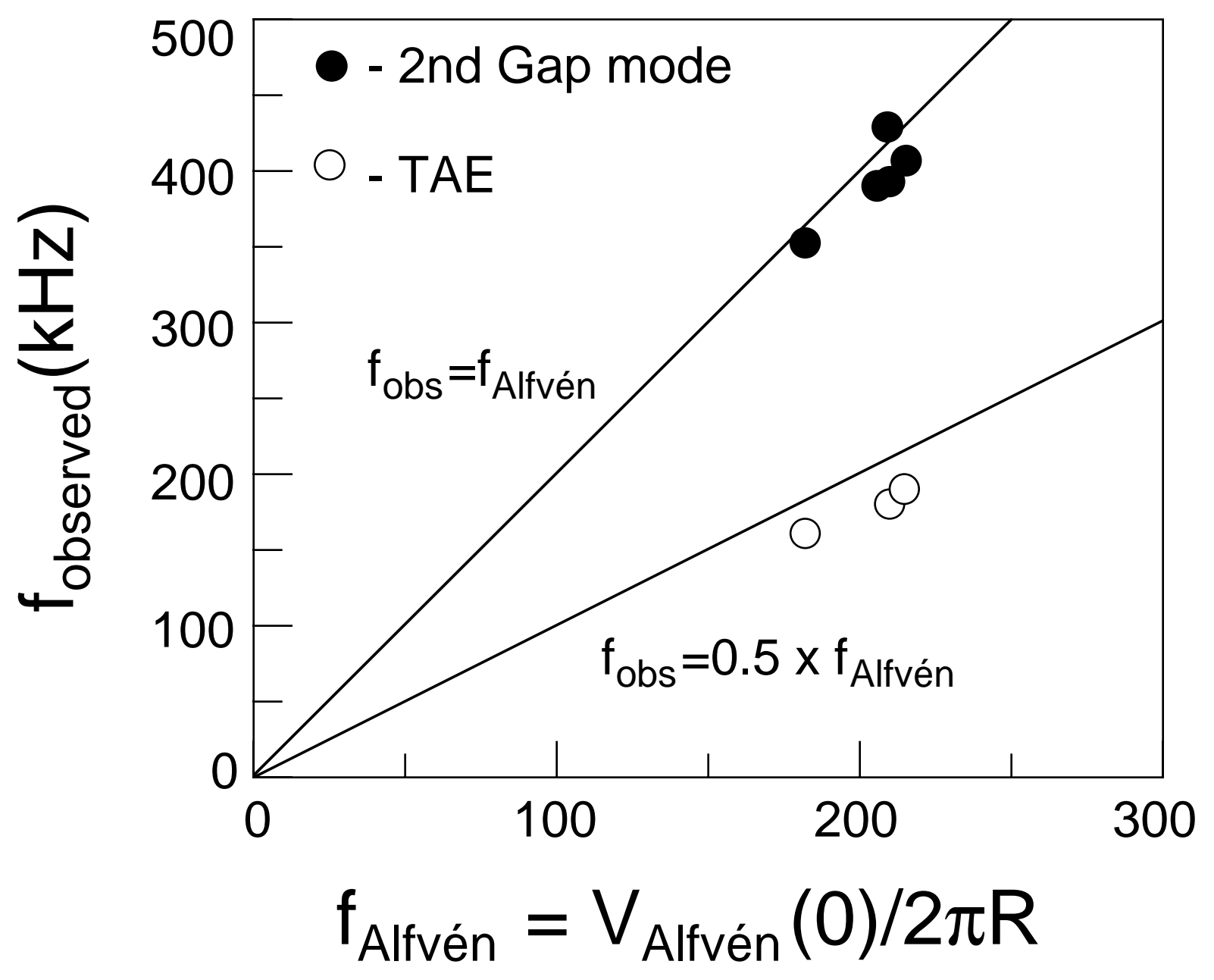




\section{Figure 4}

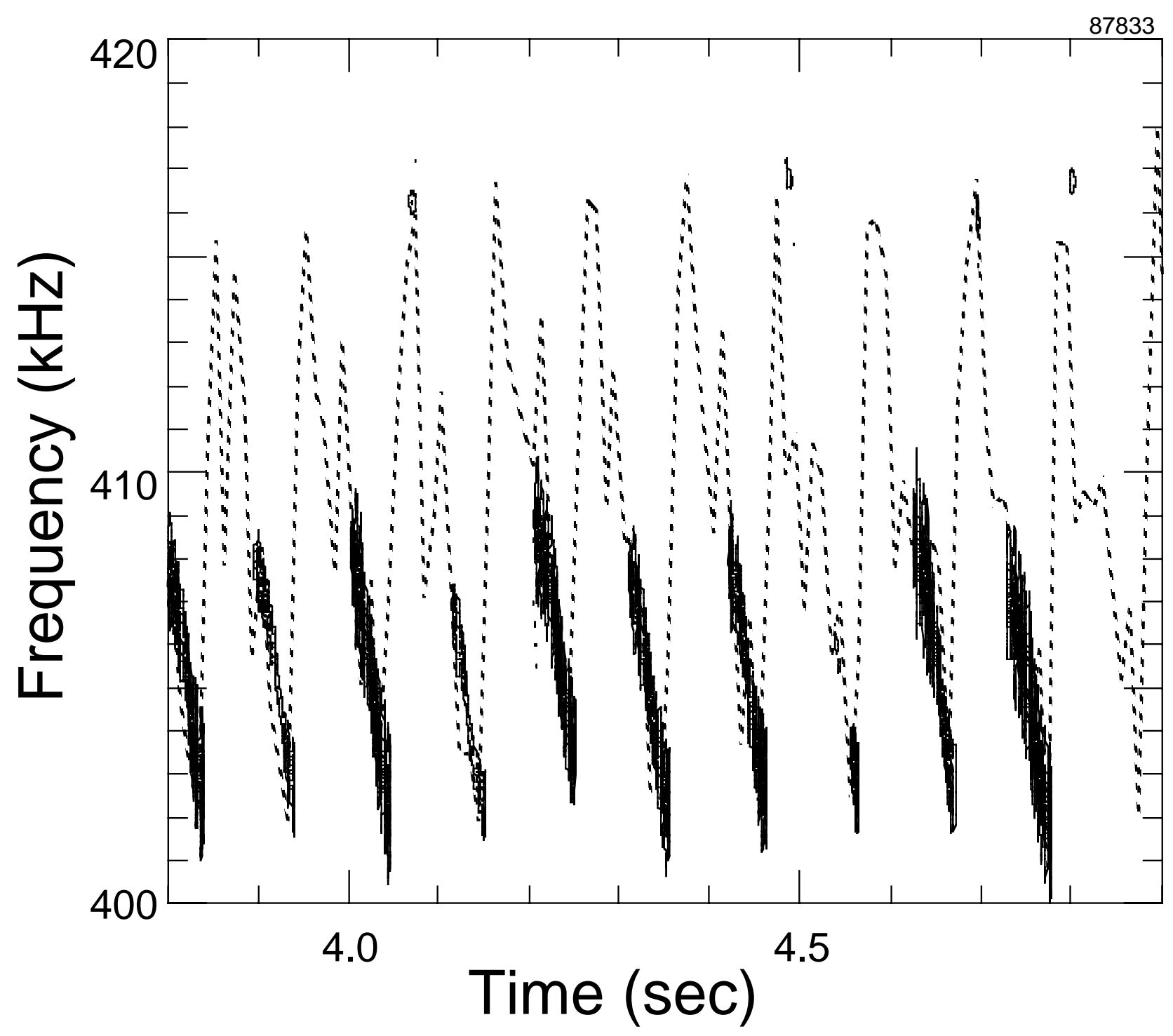


Figure 5

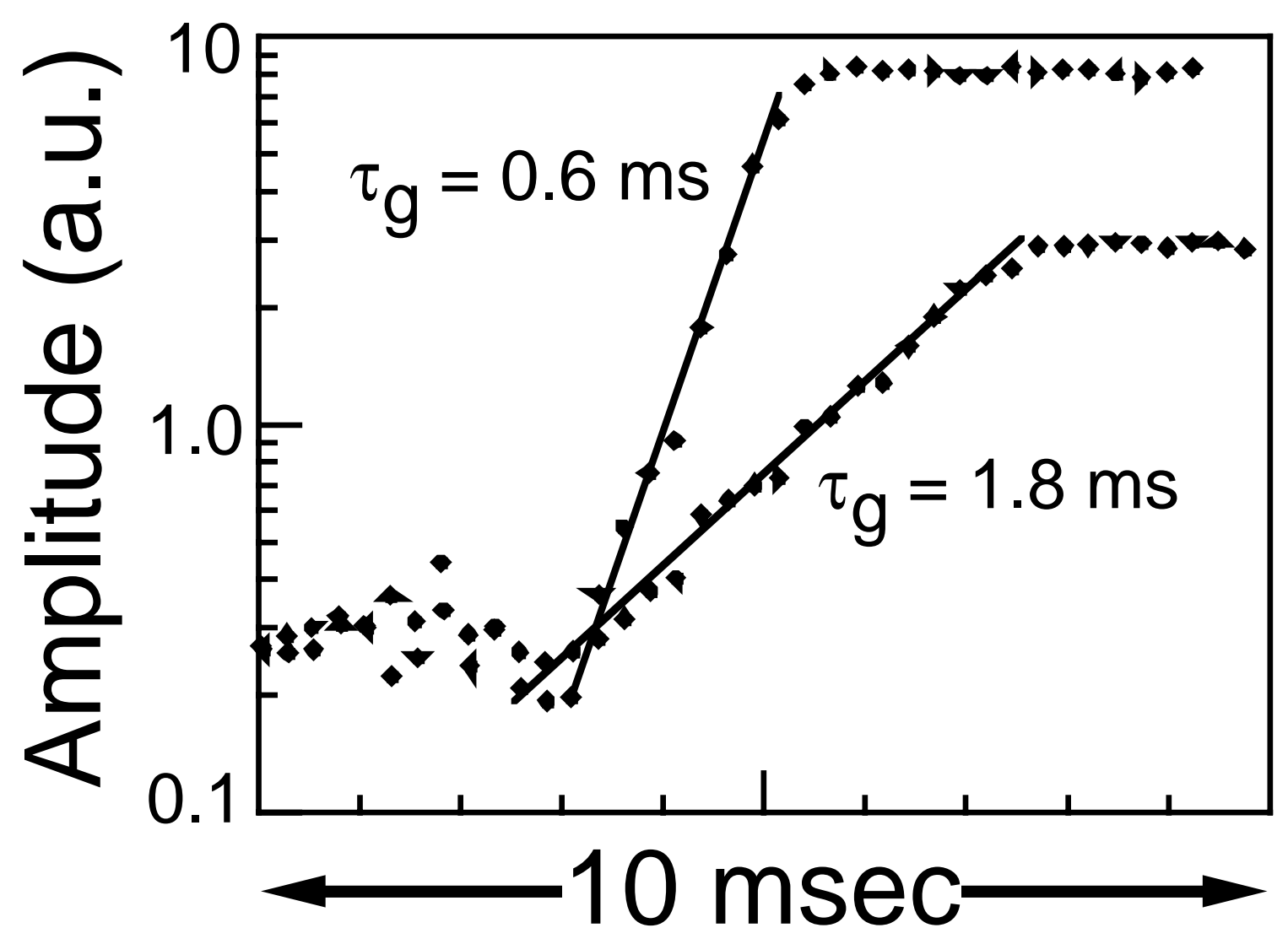


Figure 6

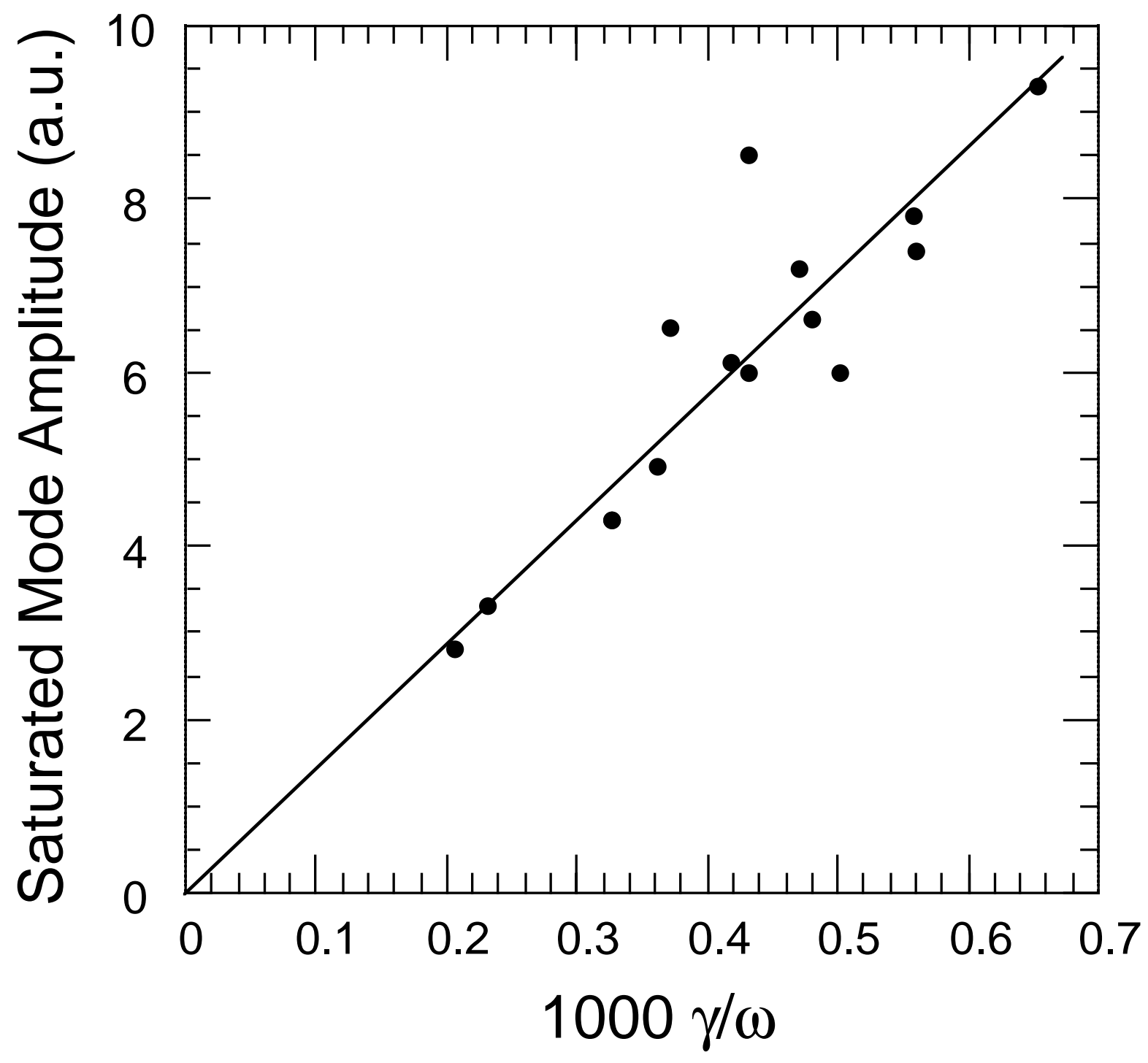


Figure 7

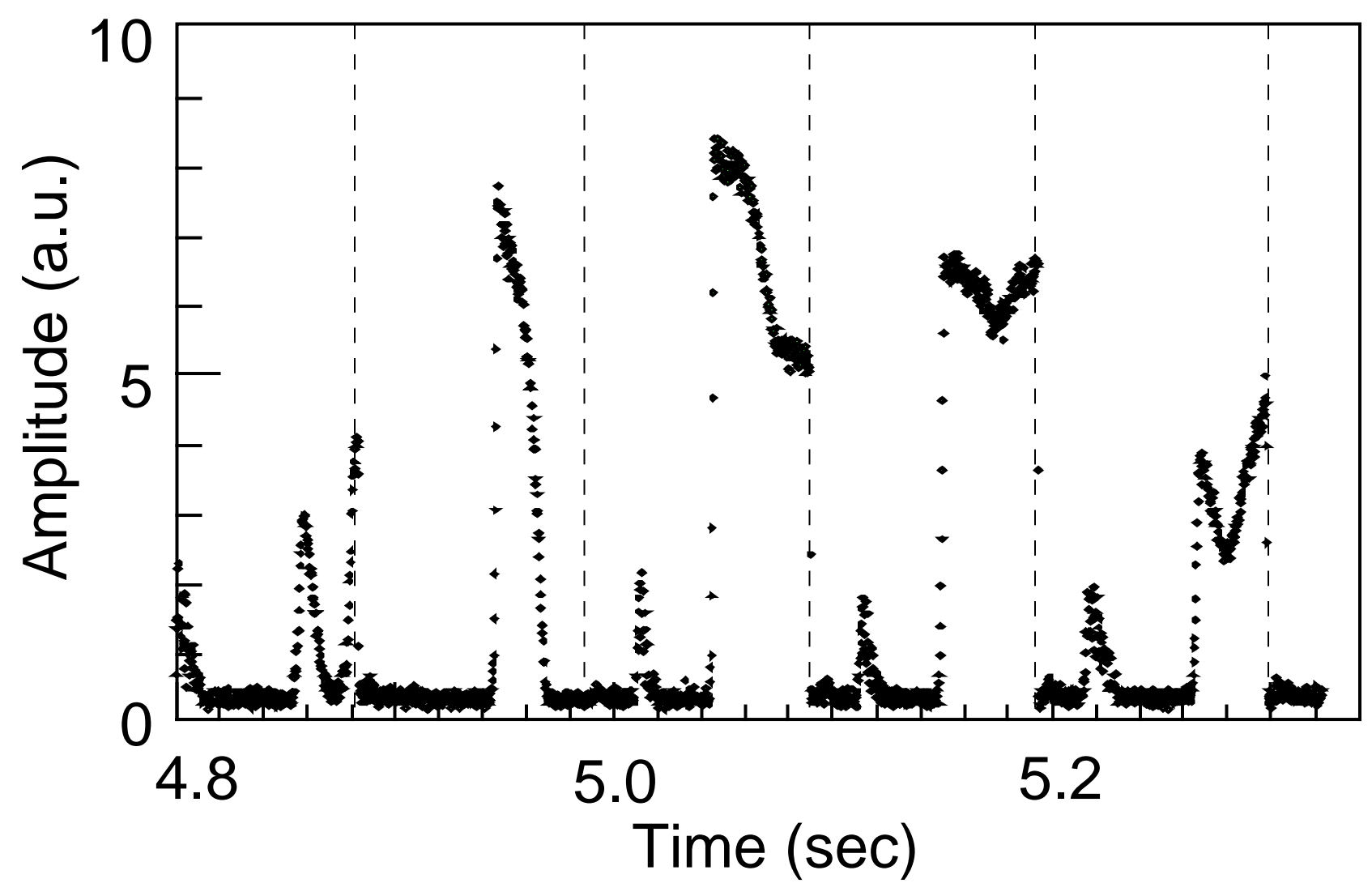


Figure 8

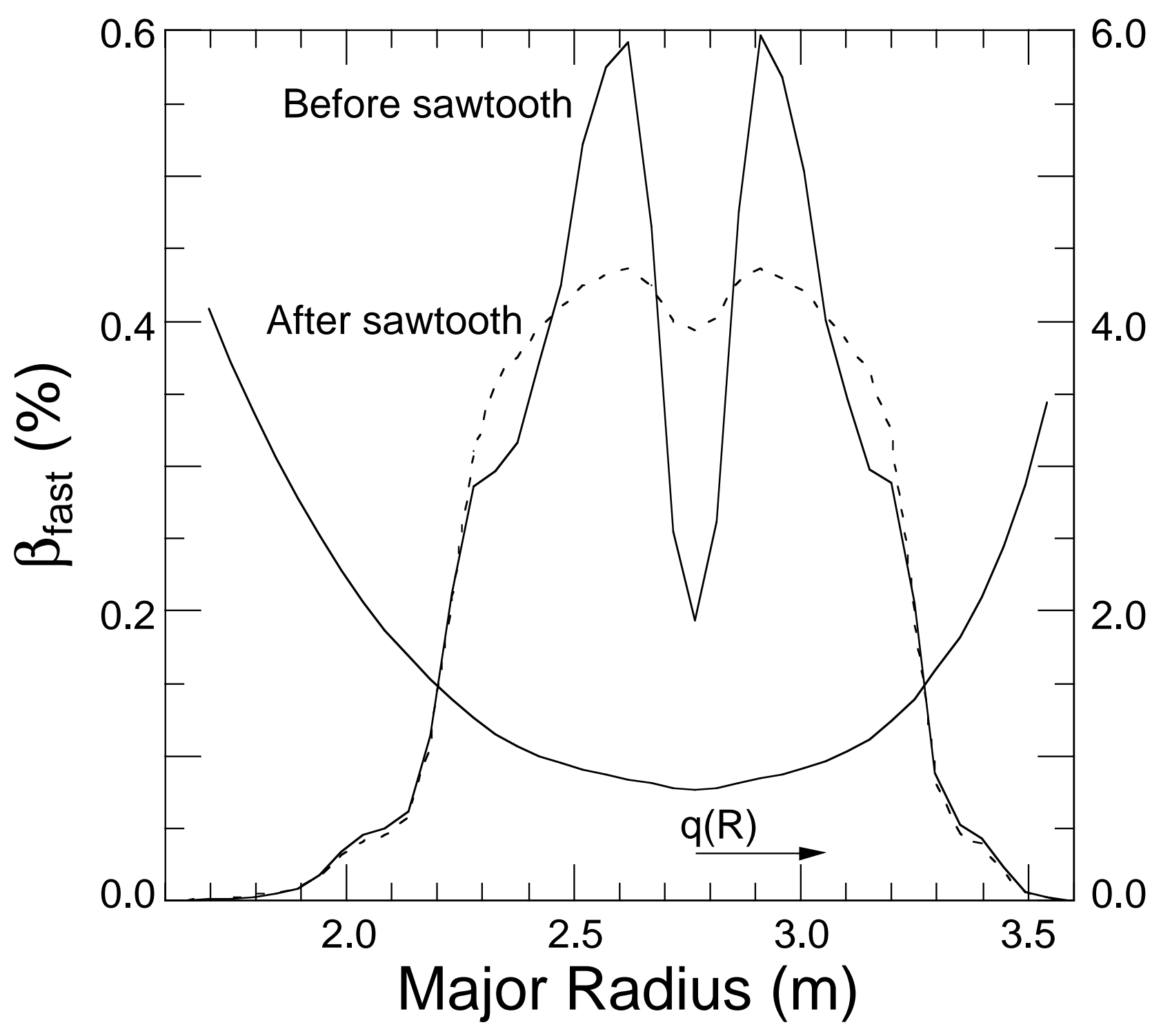


The Princeton Plasma Physics Laboratory is operated by Princeton University under contract with the U.S. Department of Energy.

\author{
Information Services \\ Princeton Plasma Physics Laboratory \\ P.O. Box 451 \\ Princeton, NJ 08543
}

Phone: 609-243-2750

Fax: 609-243-2751

e-mail: pppl_info@pppl.gov

Internet Address: http://www.pppl.gov 